\title{
Play soliciting behavior in prepubertal and postpubertal male rats
}

\author{
D. H. THOR and W. R. HOLLOWAY, JR. \\ E. R. Johnstone Training and Research Center, Bordentown, New Jersey
}

\begin{abstract}
Pre- and postpubertal play soliciting behavior was observed in intact males, castrate males, sham-operated males, and female controls. Although play soliciting decreased markedly with age in all groups, male treatment groups did not differ reliably on pre- or postpubertal tests. Males, however, engaged in reliably greater play soliciting than females on all measures in both preand postpubertal tests. These results suggest that the major decrease in social play associated with the attainment of sexual maturity is apparent in the play soliciting behavior of both sexes and may be attributed to maturation effects other than that associated with gonadal hormones. The results are discussed in reference to organizational and activational effects of male gonadal hormones on measures of social play behavior.
\end{abstract}

Takahashi and Lore (1983) recently reported longitudinal studies of social play behavior in paired male and female rats from weaning into young adulthood; paired males engaged in significantly lower levels of play than female or mixed-sex pairs after 54 days of age. This work is of particular interest because it is one of the first laboratory reports of a juvenile type of social play in adult rats. Similar findings have recently been reported by other investigators after observing relatively noncaptive colonies in large, outdoor pens (Adams \& Boice, 1983).

The findings of Takahashi and Lore (1983) also support Taylor's (1980) interpretation that juvenile social interactions predict adult aggressiveness. Furthermore, they reveal that adult social play can be measured independently of agonistic behavior. Adult play fighting behavior, like that of juveniles, is not accompanied by piloerection and is totally lacking in submissive postures. It is also of interest to note that, as animals attain sexual maturity, the quality of social play undergoes little, if any change (Adams \& Boice, 1983; Drews, Forand, Gipe, Challel, \& Gay, 1982; Takahashi \& Lore, 1983; Taylor, 1980).

Social play peaks during the developmental interval preceding puberty, that is, 30-40 days of age (Thor \& Holloway, 1984a). Thereafter, social play decreases in frequency of occurrence with some diminution in the rapidity of movement that characterizes juvenile play. One interpretation of this major change in behavioral ontogeny is related to the coincidental occurrence of sexual maturation and the morphological development of structures supporting male aggressive and sexual behaviors, namely, testicular androgens and androgen-affected systems of the CNS. Indeed, Taylor (1980) has suggested that the same physiological systems that affect adult aggressiveness may

\footnotetext{
We thank H. Spitz, J. Winters, D. Hoats, P. Conlow, and D. Lenox for their assistance on various aspects of this work. Requests for reprints may be addressed to D. H. Thor, Research Department, Johnstone Training and Research Center, Bordentown, NJ 08505.
}

affect juvenile play fighting. For example, the increase in circulating androgens associated with the onset of puberty may trigger the development of dopamine autoreceptors in the mesolimbic projection areas, which, in concert with similar endocrinological effects in other feedback systems, may fundamentally alter sensation-seeking behaviors (Spear \& Brake, 1983). A less sophisticated (but equally elusive) interpretation is simply that the increase in size and body weight associated with growth may act to dampen spontaneous physical interaction of less mature, but more nimble, juveniles.

The results of Takahashi and Lore (1983) may be interpreted as suggesting little or no direct effect of sexual maturity on social play; that is, the decline in male play fighting with age was attributed, in part, to agonistic interaction (which terminated play). Meaney and Stewart (1983) have also determined that the administration of exogenous testosterone to juvenile males does not affect the frequency of play initiation or play fighting. Conversely, neonatal exposure to testosterone has repeatedly been shown to increase juvenile social play (Beatty, Dodge, Traylor, \& Meaney, 1981; Meaney \& Stewart, 1981b; Meaney, Stewart, Poulin, \& McEwen, 1983; Olioff \& Stewart, 1978).

The present experiment was conducted to compare the play soliciting behavior of pre- and postpubertal, intact and castrate males (Thor \& Holloway, 1983). Play eliciting, inciting, or soliciting behavior is presumed to represent the initial phase of social play behavior, and to be that aspect of social play most sensitive to sex differences (Meaney \& Stewart, 1981b, p. 210). We reasoned that the use of a nonplayful, juvenile social stimulus would permit assessment of an essential aspect of social play without concern for reciprocal play behavior of the stimulus; additionally, the use of juveniles as social stimuli obviates potentially confounding aggressive behavior in males. A female control group was included to evaluate male group differences as well as potential sex differences. 


\section{METHOD}

\section{Subjects}

A subject pool of 12 litters of Long-Evans laboratory reared hooded rats was used. All litters were weaned at 21 days of age, and from this pool, one group of 12 females and three groups of 12 males each were formed. An additional pool of prepubertal males, several days younger than the subjects, provided rats used as social stimuli during prepubertal testing. A second pool of prepubertal males, of the same age as the first, provided rats used as social stimuli in postpubertal testing. Each subject was identified by ear and tail markings.

\section{Treatments}

One group of weanling males was surgically castrated under Chloropent anesthesia at 21-22 days. A second group of sham-operated males received only a scrotal incision and a single suture under anesthesia. A third group of males and the group of females were handled but untreated. After recovery, at 24 days of age, like sex and treatment pairs of weanlings were housed in standard, suspended wire-mesh cages. Purina Lab Chow pellets and water were freely available throughout. All subjects were handled at 1-3-day intervals and appeared in good health from weaning through testing (there was no attrition or substitution),

Each social stimulus, a male juvenile, was pretreated with scopolamine $\mathrm{HBr}(10 \mathrm{mg} / \mathrm{kg}) 10$ min prior to testing, as described elsewhere (Thor \& Holloway, 1983). This treatment renders the social stimulus nonplayful without diminishing social attractiveness, that is, the stimulus is normally active but does not initiate social play or respond to play soliciting by the subject. Only male juveniles were used as social stimuli, since males may be more socially attractive than females for both male and female juvenile subjects (Meaney \& Stewart, 1981a; Poole \& Fish, 1973; Thor \& Holloway, 1983, Experiment 2).

\section{Measures}

Three play soliciting frequency measures were used in addition to measures of social investigation and weight gain. A crossover is defined as a measure of social behavior by the subject that includes: crawlover, crawlunder, pounce, and any other gross movement that results in a complete traversal over or under the head or trunk of the stimulus. A dart is a rapid running movement by the subject toward, parallel to, or away from the stimulus. A crossover-dart is a combination of the two separately defined soliciting behaviors and consists of a running movement by the subject that is immediately preceded or followed by a complete traversal of the stimulus. The latter designation may be useful, since it appears to occur most often in vigorous play soliciting episodes and may constitute the most complete form of play soliciting behavior.

Social investigatory behavior by the subject of the stimulus normally precedes bouts of active play soliciting. Duration of social investigation, defined as following, sniffing, nosing, or grooming of the stimulus animal, was recorded in seconds. Each subject was weighed following each test exposure to a stimulus. Difference in pre- and postpubertal weights was defined as intertest weight gain for each subject.

\section{Procedure}

Each subject was tested individually at 30-35 days of age (prepubertally) and again at 70-75 days of age (postpubertally). Any postpubertal female in estrus was tested on the following day. Twenty-four hours prior to testing, the subject was removed from its home cage and socially isolated in a larger $(41 \times 51 \times 22 \mathrm{~cm})$, plastic-pan cage with wood-chip litter and free access to food and water. Social stimuli were maintained in group cages of several male juveniles per cage. Ten minutes prior to testing, the social stimulus was treated with scopolamine. At the start of each 6-min test exposure interval, a social stimulus was placed in the subject's test cage and timers were started. Hand-held switches were used to record social investigation time and play-soliciting frequencies. All tests were conducted in dim red light during the normally dark phase of an inverted 12:12 light-dark cycle. The observer was blind as to treatment and sex categories of the subjects.

\section{RESULTS}

Both males and females engaged in substantially less play soliciting on postpubertal tests than on prepubertal tests. Males engaged in greater play soliciting than females, but castration had no effect on play soliciting. Since male treatment groups did not differ reliably on any of the prepubertal or postpubertal tests of play soliciting or social investigation, male data were collapsed across treatment groups for all analyses of sex differences (two-way repeated measures ANOVAs). The results are summarized in Figure 1.

\section{Crossovers}

Males engaged in greater mean crossovers than females $[F(1,46)=8.49, p<.01]$, and greater mean crossovers were made prepubertally than postpubertally $[\mathrm{F}(1,46)=$ $83.39, \mathrm{p}<.001]$. The interaction was marginally significant $[F(1,46)=3.76, p<.06]$.

\section{Darts}

Males darted more frequently than females $[F(1,46)=$ $7.97, \mathrm{p}<.01]$ and darted more prepubertally than postpubertally $[F(1,46)=50.40, p<.001]$. The interaction was nonsignificant.

\section{Crossover-Darts}

Males were observed to crossover-dart more frequently than females $[F(1,46)=20.10, p<.001]$. More crossover-darts were made prepubertally than postpubertally $[F(1,46)=62.22, p<.001]$, and the interaction (sex $\times$ test) was significant $[\mathrm{F}(1,46)=5.28, \mathrm{p}<.05]$; the decrease from prepubertal to postpubertal testing was greater in males than in females (due in part to a floor effect, limiting the mean decrease in females).

\section{Total Play Soliciting Frequency}

A separate ANOVA was computed with total play soliciting frequency scores for each subject. The main ef-

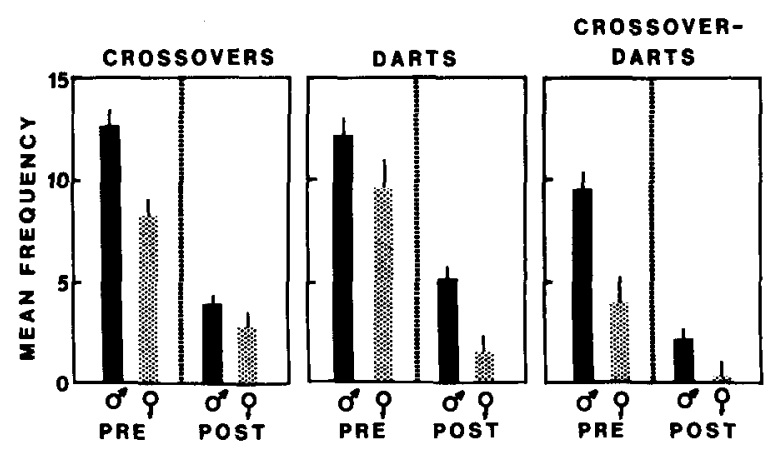

Figure 1. Means and variances (SE) of pre- and postpubertal measures of play-soliciting behavior by males and females. 
fects of sex and test were both highly significant $[F s(1,46)$ $=20.75$ and $131.27, \mathrm{p}<.001]$. The interaction was nonsignificant. A post hoc test for paired mean comparisons (Tukey HSD with correction for unequal cell frequency) indicated reliable sex differences on both prepubertal $(\mathrm{p}<.01)$ and postpubertal $(\mathrm{p}<.05)$ tests.

\section{Pre- and Postpubertal Correlation}

Total frequency of play soliciting on pre- and postpubertal tests was positively and reliably $(\mathrm{p}<.05)$ correlated for males $(r=.38)$ and nonreliably correlated for females. All correlations for castrates were nonreliable, that is, on individual soliciting measures as well as on the total frequency measure. However, the correlations for intact males were reliable for crossover $(r=.40)$, crossoverdart $(r=.41)$, and total frequency $(r=.54)$ measures. All correlations are given in Table 1 .

\section{Social Investigation}

Investigation time increased on the postpubertal test $[F(1,46)=30.97, p<.001]$, and males increased their social investigation more than did females $[F(1,46)=$ $5.49, \mathrm{p}<.025]$. The main effect of sex was nonsignificant, but post hoc analyses for mean sex differences on the prepubertal (males, 105.9 $\pm 3.9 \mathrm{sec}$; females, $119.6 \pm 7.3 \mathrm{sec}$ ) and postpubertal (males, $155.2 \pm 4.2 \mathrm{sec}$; females, $140.5 \pm 8.2 \mathrm{sec}$ ) tests were both marginally significant $(p<.10)$.

\section{Weight Gain}

Females gained a mean of $124.6 \mathrm{~g}$. Mean weight gain of the male groups differed significantly $[\mathrm{F}(2,33)=6.16$, $\mathrm{p}<.01$, with less weight gained by castrate males $(184.7 \mathrm{~g})$ than by intact $(201.2 \mathrm{~g})$ or sham-operated $(205.6 \mathrm{~g})$ males.

To determine if the heavier members of home cage pairs engaged in greater mean play solicitation than the lighter members, total frequency of play soliciting by each subject was tabulated according to heavier or lighter withinpair designation. On separate ANOVAs, for pre- and postpubertal data (sex $\times$ weight), heavy and light categories did not differ significantly and the interactions with sex were nonsignificant. Correlations of body weight with frequency of play soliciting were nonsignificant for both male and female subjects on both pre- and postpubertal tests.

Table 1

Correlations of the Frequency of Play Soliciting on Pre- and Postpubertal Tests

\begin{tabular}{ccccc} 
Group & Crossover & Dart & Dart & Total \\
\hline Females & .08 & -.32 & .00 & -.28 \\
Males & $.28 *$ & .05 & $.41 \dagger$ & $.38 \dagger$ \\
Intacts & $.40 \dagger$ & .25 & $.41 \dagger$ & $.54 \ddagger$ \\
Castrates & .10 & -.41 & .38 & -.05 \\
\hline
\end{tabular}

${ }^{*} p<.10 . \quad \dagger p<.05 . \quad \neq p<.01$.

\section{DISCUSSION}

Play soliciting behavior of castrate and intact males suggests than any activational or pubertal effect of gonadal androgens is minimal or nonexistent, at least in reference to play initiation. This finding supports the conclusion reached by Meaney and Stewart (1983) that, in juveniles, exogenous testosterone is without effect on play fighting initiation or performance and extends their interpretation by comparison of intact and prepubertal castrates in a different test paradigm, using paired exposure to a nonplayful social stimulus and with young adults as well as with juveniles. Since castrates did not differ from intact males prepubertally or postpubertally, the present results further suggest that no gonadal androgen has any conspicuous role in the curtailment of juvenile play that normally coincides with the advent of sexual maturity.

The only effect attributed to castration was the negative effect on weight gain, castrates gaining less than intact male groups. Absence of a castration effect on social play in prepubertal males has also been reported by Beatty et al. (1981), who found no effect on juvenile social play of castration at 10 or more days of age. Meaney and Stewart (1981b) have also reported no difference in the social play of 23-day-old castrates when compared with intact males at 31-40 days of age.

Puberty is marked by radical physiological and behavioral changes attributed to gain in gonadal output (Zillman, 1984). The present results, in addition to those of other reports detailing the absence of pubertal androgen effects on social play, may tentatively be interpreted as discounting juvenile social play as a precursor of sexual or aggressive behaviors. Others have emphasized that the juvenile social play of rodents is not a necessary requirement for the adequate performance of adult social behaviors, that is, attempts to demonstrate any adult deficit by withholding play experience have been negative or inconclusive. A recent theoretical analysis of social play function has postulated that juvenile play may be the primary, initial impetus to engage in spontaneous social interaction and may thus serve to repeatedly bring the individual into physical contact with its social group (Meaney, Stewart, \& Beatty, 1985). Other theorists have proposed that social play is an immature form of adult behavior (Takahashi \& Lore, 1983; Taylor, 1980) or a form of practice for adult interaction (Panksepp, Siviy, \& Normansell, 1984). At present, there is no conclusive evidence or convincing demonstration that can deal with the essential question: What is the biological function of social play?

Sex differences on prepubertal testing confirm previous observations of sex differences in juvenile play soliciting behavior (Thor \& Holloway, 1983). Postpubertal sex differences also suggest that endogenous gonadal androgen exposure (occurring several days before and several days after birth) may have organizational effects on so- 
cial interaction that extend beyond puberty. Perinatal gonadal androgen effects (Meaney \& Stewart, 1981b; Meaney et al., 1983; Olioff \& Stewart, 1978) have generally been limited to observations of prepubertal social play behavior.

Positive correlations of the frequency of play soliciting by males on pre- and postpubertal tests support the suggestion that, at least with intact males, some aspects of social interaction in juveniles are predictive of social interaction in maturity (Adams \& Boice, 1983; Takahashi \& Lore, 1983; Taylor, 1980). The crossover-dart indicator appears to present a potentially useful measure of play soliciting behavior.

Implications of this and related work include the affirmation of the recent discovery that, although social play and social aggression share some superficial aspects of appearance (juvenile play fighting resembles adult fighting), they differ markedly in reference to eliciting stimuli as well as hormonal underpinnings (for recent reviews, see Beatty, 1984; Meaney et al., 1985; Thor \& Holloway, 1984b). At the present time, only a perinatal or organizational effect of gonadal androgens has been demonstrated as influential in modifying the social interaction commonly defined as play behavior. Determination of the neurological and/or growth-related variables that effect the marked decrease in the social play of both sexes, coincidental with the onset of sexual maturity, remains an open question.

\section{REFERENCES}

Adams, N., \& Boice, R. (1983). A longitudinal study of dominance in an outdoor colony of domestic rats. Journal of Comparative Psychology, 97, 24-33.

Beatty, W. W. (1984). Hormonal organization of sex differences in play fighting and spatial behavior. In G. J. DeVries, J. P. C. DeBruin, H. B. M. Uylings, \& M. A. Comer (Eds.), Progress in brain research: Vol. 61. Sex differences in the brain. Amsterdam: Elsevier.

Beatty, W. W., Dodge, A. M., Traylor, K. L., \& Meaney, M. J. (1981). Temporal boundary of the sensitive period for hormonal organization of social play in juvenile rats. Physiology \& Behavior, 26, 241-243.

Drews, D. R., Forand, K. J., Gipe, T. G., Challel, L. D., \& Gay,
R. I. (1982). A descriptive study of social development in family groups of rats. Bulletin of the Psychonomic Society, 19, 177-180.

Meaney, M. J., \& Stewart, J. (1981a). A descriptive study of social development in the rat (Rattus norvegicus). Animal Behaviour, 29, 34-45.

MEANEY, M. J., \& STEWART, J. (1981b). Neonatal androgens influence the social play of prepubescent rats. Hormones \& Behavior, 15 , 197-213.

Meaney, M. J., \& Stewart, J. (1983). The influence of exogenous testosterone and corticosterone on the social behavior of prepubertal male rats. Bulletin of the Psychonomic Society, 21, 232-234.

Meaney, M. J., Stewart, J., \& Beatty, W. W. (1985). Sex differences in social play: The socialization of sex roles. In J. Rosenblatt, C. Beer, M. Claire-Busnel, \& P. J. B. Slater (Eds.), Advances in the study of behavior (Vol. 15). Academic Press: New York.

Meaney, M. J., Stewart, J., Poulin, P., \& McEwen, B. S. (1983). Sexual differentiation of social play in rat pups is mediated by the neonatal androgen-receptor system. Neuroendocrinology, 37, 85-90.

OUOFF, M., STEWART, J. (1978). Sex differences in the play behavior of prepubescent rats. Physiology \& Behavior, 20, 113-115.

PanksePP, J., Siviy, S., \& Normansell, L. (1984). The psychobiology of play: Theoretical and methodological considerations. Neuroscience \& Biobehavioral Reviews, 8, 465-492.

PoOle, T. B., \& Fish, J. (1976). An investigation of individual, age, and sexual differences in the play of Rattus norvegicus (Mammalia: Rodentia). Journal of the Zoological Society, London, 179, 249-260.

SPEAR, L. P, \& Brake, S. C. (1983). Periadolescence: Age-dependent behavior and psychopharmacological responsivity in rats. Developmental Psychobiology, 16, 83-109.

TAKahashi, L. K., \& LoRe, R. K. (1983). Play fighting and the development of agonistic behavior in male and female rats. Aggressive Behavior, 9, 217-227.

TAYLOR, G. T. (1980). Fighting in juvenile rats and the ontogeny of agonistic behavior. Joumal of Comparative \& Physiological Psychology, 94, 953-961.

Thor, D. H., \& Holloway, W. R., Jr. (1983). Play-solicitation behavior in juvenile male and female rats. Animal Learning \& Behavior, 11, 173-178.

Thor, D. H., \& Holloway, W. R., JR. (1984a). Developmental analyses of social play behavior. Bulletin of the Psychonomic Society, 22, 587-590.

THOR, D. H., \& Holloway, W. R., JR. (1984b). Social play in juvenile rats: A decade of methodological and experimental research. Neuroscience \& Biobehavioral Reviews, 8, 455-464.

Zillman, D. (1984). Connections between sex and aggression. Hillsdale, NJ: Erlbaum.

(Manuscript received December 13, 1984; revision accepted for publication May 28, 1985.) 